\title{
Promotoras Legais Populares: a construção de pontes para a cidadania feminina
}

\author{
Promotoras Legais Populares :building bridges for female citizenship
}

\begin{abstract}
Julia Glaciela Oliveira*
\section{Resumo}

O presente artigo visa apresentar uma experiência do curso de "Promotoras Legais Populares" (PLP), realizada pela associação feminista "União de Mulheres de São Paulo" (UMSP), desde 1994. A associação autônoma feminista foi fundada em 1981 com o intuito de lutar pelos direitos das mulheres e pelas liberdades democráticas. No início dos anos de 1990, a entidade, em parceria com a ONG feminista Themis, de Porto Alegre, trouxe para o Brasil a inciativa do curso de educação jurídica popular, adotado por outras associações feministas da América Latina. A proposta do curso é ensinar às mulheres noções básicas de Direito e Cidadania, para que as mesmas tomem posse do discurso jurídico e saibam utilizá-lo em sua comunidade e em suas vidas como mecanismo de resistência às assimetrias sociais, étnicas e de gênero. Do mesmo modo, o conhecimento dos discursos patriarcais permite que as mulheres desconstruam a identidade feminina vista como destino natural e construam outras possibilidades de existência.
\end{abstract}

Palavras-chave: feminismos; educação jurídica; direitos humanos; gênero.

\begin{abstract}
:
This article presents the experience of the course "Promotoras Legais Populares" (PLP), conducted by feminist association "União de Mulheres de São Paulo" ( UMSP ) , since 1994. The autonomous feminist association was founded in 1981 with the intention of fighting for women's rights and democratic freedoms. In early 1990, the entity with feminist ONG Themis, Porto Alegre, Brazil brought to the initiative of the popular legal education course adopted by other feminist associations in Latin America . The purpose of the course is to teach women the basics of law and citizenship, allowing them to take ownership of the legal discourse and learn to use it in their community and in their lives as a mechanism of resistance to social inequalities, ethnic, and gender. Similarly, knowledge about the patriarchal discourses allow women to deconstruct the female identity seen as natural destiny and build other possibilities of existence.
\end{abstract}

Key words: feminisms, legal education, human rights, gender.

\footnotetext{
* Mestre em História Cultural pela Universidade Estadual de Campinas - UNICAMP (2013) e graduada em História pela Universidade Estadual de Londrina - UEL (2006). julia.gsoliveira@gmail.com
} 


\section{Introdução}

A União de Mulheres de São Paulo (UMSP) foi fundada em 1981, em São Paulo, por militantes de partidos políticos de esquerda, como Criméia Almeida, Terezinha Gonzaga e Amelinha Teles, que, diante da resistência dos dirigentes desses partidos aos temas femininos, resolveram construir um espaço destinado, exclusivamente, a essas questões. Desde sua fundação, a UMSP esteve envolvida na luta pelas liberdades civis e pelos direitos das mulheres. Participou efetivamente da luta por creches, das discussões sobre a licença paternidade e esteve à frente das campanhas pela Constituição, em 1988, e do movimento pela descriminalização do aborto no mesmo período. Portanto, a trajetória da associação foi marcada pela militância em favor das liberdades políticas e da equidade de gênero.

Ainda na década de 1980, os movimentos feministas conseguiram que muitas de suas demandas fossem asseguradas pelo Estado. Foram criadas secretarias especiais para as mulheres, bem como, a primeira delegacia especializada no atendimento às vítimas de violência de gênero, além de novos artigos na Carta Constitucional, que visavam a acabar com as medidas patriarcais e assimétricas em relação às mulheres. Contudo, após as conquistas estabelecidas pela Constituição, havia a necessidade de se construir uma ponte para que estas fossem efetivadas, pois, como afirma Gregori e Debret (2008), mesmo com uma das cartas constitucionais mais avançadas, ainda "vivemos em meio a uma persistente desigualdade social no acesso à justiça" (2008, p. 167)".

É nesse contexto que, em 1994, a UMSP adotou o projeto de educação jurídica popular, ou capacitação legal, intitulado de "Promotoras Legais Populares" (PLP). Em 1992, o CLADEM (Comitê Latino Americano e do Caribe para a Defesa dos Direitos das Mulheres) ${ }^{1}$ ofereceu um curso no Brasil, no qual foi apresentada a experiência dos grupos de capacitação legal que vinham sendo desenvolvidos em países como Argentina, Chile e Peru.

A UMSP e a ONG feminista Themis, de Porto Alegre, participaram do curso oferecido pelo CLADEM e resolveram implantar a proposta no Brasil. Segundo Amelinha, que participou do evento ao lado de Denise Dora, da Themis, o projeto foi visto como uma importante ferramenta para as feministas, pois: "Era um momento de grande desafio:

\footnotetext{
${ }^{1}$ O CLADEM foi fundado em 1987, em San Jose da Costa Rica, e tem uma sede no Brasil desde 1992. Atualmente, tem sede em 16 dos 24 países da América Latina. Disponível em:<http://www.cladem.org>. Acessado em 24/07/2013.
} 
afinal havíamos conquistados direitos fundamentais na Constituição de 1988, mas como fazê-los valer?" (TELES, 2011). Em 1993, a Themis iniciou o primeiro curso de Promotoras Legais Populares (PLP) e, no ano seguinte, a primeira turma foi organizada em São Paulo pela UMSP. Na percepção de Amelinha "o projeto revigorou a luta pela cidadania, pelo empoderamento e reconhecimento dos Direitos Humanos das Mulheres (...) e tem revigorado o próprio feminismo" (idem).

Em linhas gerais, o curso de Promotoras Legais Populares visa a ensinar às mulheres noções básicas de Direito, cidadania, funcionamento do Estado e organização das leis, a partir de uma perspectiva de gênero. Desse modo, o curso possibilita, para além de um aprendizado jurídico, a compreensão das formas de discriminação e exclusão das mulheres da vida social e política. ${ }^{2}$ Assim sendo, o objetivo do curso não é apenas a divulgação da lei, mas, sobretudo, fazer com que o conhecimento do Direito possa ser utilizado como um meio de pressão política e como agente transformador da linguagem jurídica, bem como, da vida das próprias mulheres.

Hoje, através da teia construída pela UMSP e pela Themis, há uma rede de Promotoras Legais Populares sendo desenvolvido, de diferentes formas, em cidades do interior paulista, como Sorocaba, Taboão da Serra, Santo André, Rio Claro e São José dos Campos, assim como, em alguns estados do nordeste, como Pernambuco, e do norte do país, como o Amazonas.

Em São Paulo, o curso realizado pela UMSP ocorre no prédio da Secretária da Justiça e da Defesa da Cidadania, no centro da cidade, em parceria com o IBAP (Instituto Brasileiro de Advocacia Pública) e com o MPD (Movimento do Ministério Público Democrático), aos sábados, das 09hs às $13 \mathrm{hs}$, com duração de um ano. As aulas são ministradas por pessoas da área jurídica, como advogada(o)s, juíza(e)s e promotora(e)s, e por outros profissionais, como médicas, sociólogas, psicólogas e ainda por ativistas de movimentos sociais. As alunas, durante o ano, também realizam visitas a órgãos públicos, como a Delegacia de Defesa da Mulher.

\section{Pontes para cidadania pelo olhar feminista}

\footnotetext{
2 Ver: OLIVEIRA, Fernanda Fernandes. Quando o Direito Encontra a Rua. Dissertação de Mestrado, Faculdade de Educação, Universidade de São Paulo, 2006.
} 
Terezinha, militante da UMSP, ao relembrar sobre o momento em que tudo começou, narra que a iniciativa do projeto atendia as necessidades da campanha "Tem que valer nossos direitos", realizada por movimentos feministas com o intuito de ver asseguradas as novas conquistas de gênero no campo político. Assim, em sua leitura, o curso possibilitou a construção de uma ponte entre os novos direitos e o acesso à cidadania. Ensinar as mulheres sobre seus direitos é percebido por ela como uma maneira de disseminar, de forma mais ampla, as informações sobre os novos direitos adquiridos. De acordo com sua narrativa:

\begin{abstract}
O projeto de Promotoras Legais Populares inicia justamente quando a gente se dá conta de que a melhor Constituinte do mundo, que garante todos os direitos, não foi considerada aplicável pelos juristas. Eles exigiram que se fizessem leis extraordinárias regulamentando os artigos da Constituição e continuaram usando as leis antigas. $O$ que é um absurdo, já que você tem uma carta magna nova e enterra as leis anteriores! Isso pela lógica, mas no nosso país o patriarcalismo e patrimonialismo não deixam isso acontecer. Então, nós ganhamos, mas não levamos e aí nós saímos com a campanha "Tem que valer nossos direitos". E o projeto de Promotoras Legais Populares é dessa época. E quando nós discutimos a gente vê que era uma forma de nós divulgarmos a Constituição, pois, desde que ela foi outorgada ela estava ameaçada e para isso teria que estudar a Constituição e o curso de Promotoras é isso, a gente estuda os direitos individuais (OLIVEIRA, 2012).
\end{abstract}

As iniciativas de capacitação ou educação popular jurídica já eram realizadas desde os anos de 1980, em diversos países, como forma de promover o avanço e a justiça social para determinados grupos. O economista Stephen Golub (2010) afirma que, nas últimas décadas, principalmente em países com alto índice de desigualdade social, tem crescido o papel dos paralegais, isto é, de "pessoas com treinamento especializado que proveem auxílio jurídico a grupos desfavorecidos e que são, frequentemente, membros destes grupos" (2010, p. 167). Os paralegais oferecem apoio ou capacitação jurídica como forma de criar mecanismos para o exercício da cidadania e para o acesso ao sistema jurídico. Segundo o autor, essas propostas, a princípio, surgiram de uma necessidade de informação sobre os direitos, passando, posteriormente, por um processo de questionamento dos próprios princípios legais que, ainda que garantidos, não asseguravam as mudanças sociais nas representações de gênero ou etnia, por exemplo. Essas iniciativas têm sido realizadas em países como Namíbia, África do Sul, China, Filipinas, Quênia e Índia, onde o 
conhecimento jurídico é distribuído para agricultores e populações indígenas, entre outras minorias.

Ainda de acordo com Golub (2010), a atividade dos paralegais aproxima-se do que as advogadas feministas, como Margaret Schuler e Sakuntala Kadirgamar-Rajasingham (1992), têm defendido como legal literacy. As autoras definem a expressão como "processo de aquisição crítica de consciência sobre as leis e os direitos, a habilidade para fazer valer seus direitos e a capacidade de mobilizações a fim de gerar mudanças na sociedade" (1992, p. 298). De acordo com as mesmas, esses cursos atuam como forma de pressão política e como um agente de transformação na vida das próprias mulheres.

Segundo as autoras, em 1985, durante a III Conferência da Mulher, realizada em Nairóbi, as ativistas e operadoras do Direito reuniram-se no Fórum "Mulher, Lei e Desenvolvimento", a fim de discutir as prioridades na luta pelos direitos das mulheres. Um dos pontos discutidos foi a campanha "Conheça os seus direitos", que tinha por objetivo "empoderar" as mulheres a partir da popularização da linguagem jurídica e da criação de estratégias para a desmistificação das leis, de modo a torná-las acessíveis.

Na América Latina, o curso já era realizado por entidades feministas do Chile, da Argentina e do Peru. Ricoldi (2005) afirma que as iniciativas latino-americanas são realizadas por grupos criados entre o final da década de 1970 e meados da década de 1980, que têm, em comum, além das preocupações de gênero, a aproximação com o campo do Direito. De acordo com a autora:

\begin{abstract}
São organizações de mulheres que desenvolvem algum tipo de trabalho ligado ao mundo jurídico, que pode ser atendimento e orientação jurídica a mulheres. O perfil destas organizações pode ser mais próximo do mundo jurídico, constituindo-se predominantemente por advogadas, ou com uma formação mais mista. Porém são organizações de orientação feminista, cujo enfoque está no atendimento a mulheres, sob a perspectiva de uma maior vulnerabilidade destas, devido à discriminação e situação de subordinação. (...) Daí surgem estratégias de ação, que podem ser cursos específicos voltados para objetivos pontuais, seminários, oficinas etc. (2005, p.32).
\end{abstract}

Os movimentos feministas e de mulheres, do Brasil, da Argentina e do Peru, surgiram no contexto de luta contra os regimes militares que atuaram na América Latina entre as décadas de 1960 e 1980. Portanto, muitas de suas demandas passaram pela crítica ao Direito e pela alteração não apenas das leis que restringiam as liberdades democráticas, 
mas também das que diziam respeito à normatização do corpo feminino ou à concepção de família. Criméia, fundadora da UMSP que participou da Guerrilha do Araguaia, ao narrar suas memórias sobre a aproximação da associação e as lutas no campo jurídico, localiza sua fala nessa chave de interpretação. Ela avalia que, ao mesmo tempo em que os movimentos feministas lutavam contra as medidas legislativas do regime militar, teciam olhares críticos para as formas como o Código Civil e o Penal tratavam as mulheres. Segundo Criméia:

Na verdade, o movimento feminista e a União de Mulheres começam na luta contra a ditadura. Então, essa questão das mudanças nas leis, mesmo não acreditando muito na aplicação, isto está muito forte nesta turma. Porque é uma turma que está brigando contra a lei de Segurança Nacional, contra o Al-5, pela Constituinte. E nesse tempo começa também a briga contra o Código Civil que era um terror. O pai pode deserdar a filha desonrada, e é filha, no feminino! (ALMEIDA, 20110).

Por esse caminho, em 1982, foi criada, na América Latina, a Rede de Mulheres e Educação de Adultos, que passou a organizar encontros sub-regionais para discutir metodologias viáveis e dar apoio ao movimento de mulheres. Essa iniciativa foi influenciada pela perspectiva da educação popular de Paulo Freire, dos anos de 1970 e 1980. Nesse momento, as entidades feministas realizaram o Seminário Feminismo $e$ Educação Popular na América Latina, seguido pelo II Encontro Feminista Latino Americano, em 1983, em Lima, e pelo Encontro de Intervenção-Ação e Mulher, também em 1983, em Santiago no Chile.

Segundo Rosero (1987), a educação jurídica realizada pelas feministas latinoamericanas tem como proposta partir das experiências cotidianas das mulheres, interpretá-las e projetá-las no contexto social. Essa perspectiva busca fazer com que as mulheres desmistifiquem a visão que elas têm sobre seu papel na sociedade, para que possam construir novos olhares sobre si. Conforme a autora, embora não se possa falar em "identidade" das mulheres latino-americanas, pois há inúmeras diferenças, é importante reconhecer a existência de experiências plurais que cruzam situações comuns, como a heteronormatividade compulsória ou as relações com a maternidade, para que se possa dar visibilidade às formas de discriminação de gênero que recortam seus cotidianos. Em sua análise: 
A perspectiva feminista da educação popular coloca a necessidade de partir da própria realidade das mulheres, revalorizando o espaço doméstico, o papel reprodutivo da mulher, sua sexualidade, seu direito ao prazer, como ser humano, não para manter-Ihes como instrumento de opressão, mas para transformar em instrumentos de luta e libertação (ROSERO, 1987, p. 43).

Assim, a partir de experiências femininas atravessadas não apenas pelas assimetrias de gênero, mas, também, por outras, como as étnicas ou de classe, pretende-se fazer com que haja_uma reflexão em torno do lugar construído, cultural e socialmente, como lócus do feminino. De acordo com Tamayo (1991), o primeiro grupo feminista latino-americano a desenvolver cursos de capacitação jurídica foi a associação peruana Flora Tristan, fundada em 1979, em Lima. O intuito do grupo era utilizar a informação jurídica para acabar com os silêncios em torno da violência doméstica e sexual e fortalecer as mulheres para que conseguissem romper com essas situações e, ao mesmo tempo, impulsionar a busca pelas demandas jurídicas e de políticas públicas. Essa atividade era desenvolvida paralelamente a outras frentes de atuação, como o "serviço legal", um centro de orientação e resolução de conflitos, e uma proposta de investigação das questões jurídicas a partir da perspectiva de gênero, que incluía estudos de caso. Tamayo (1991) afirma que, entre os objetivos do curso desenvolvido pela Flora Tristan, estava o de estimular as mulheres a se tornarem "sujeitos de direitos", isto é, a conhecerem seus direitos e reivindicá-los.

Esse é o caminho pelo qual a UMSP também segue, ou seja, tratar das questões jurídicas pelo cotidiano das mulheres, não apenas no que tange à experiência própria de ser mulher, que a posiciona como um corpo mais vulnerável às formas de violência, sejam elas urbanas ou de gênero, mas, também, no que diz respeito à construção cultural de sua subjetividade, direcionada para o cuidado do outro, que a coloca diante de conflitos ligados ao marido, filhos, pais ou mesmo à comunidade.

Apesar de o foco ser as situações femininas, o projeto de PLPs também explora as discriminações e violações que ocorrem em todas as esferas sociais, para que as participantes sintam-se capazes de resolver os problemas e conflitos que vivenciam em suas vidas e no seu entorno. Na Carta de Princípios, que trata dos objetivos do curso, é enfatizada a importância de se "democratizar" o conhecimento dos direitos, para que este possa servir como forma de orientação para o reconhecimento das assimetrias que dificultam o acesso à justiça por determinados grupos. Como é exposto na Carta: 
1) Criar nas mulheres uma consciência a respeito de seus direitos como pessoa e como mulher de modo a transformá-la em sujeito de direitos; 2)Desenvolver uma consciência crítica a respeito da legislação existente e dos mecanismos disponíveis para aplicá-la de maneira a combater o sexismo e o elitismo 3)Promover um processo de democratização do conhecimento jurídico e legal (...) 5)Criar condições para que as participantes possam orientar outras mulheres em defesa de seus direitos 6) Estimular as participantes para que multipliquem os conhecimentos conjuntamente produzidos, nos movimentos que atuam. ${ }^{3}$

No caso brasileiro, o projeto de PLP veio de encontro às campanhas dos movimentos feministas pela garantia dos direitos conquistados em 1988 e pela declaração dos Direitos Humanos das Mulheres, em 1993. No entanto, a proposta de educação jurídica popular deparou-se, também, com a Lei no 9.099, de 1995, que estabeleceu os Juizados Especiais Cíveis e Criminais (JECrim), que se propõem a acabar com a morosidade jurídica, entretanto, em relação ao combate à violência contra as mulheres, sobretudo, no espaço doméstico, representou um grande retrocesso. É nessa direção que um dos pontos mais ressaltados pela UMSP, no curso de PLPs, é a relação do Direito com as formas de violência de gênero.

Amelinha, também fundadora da UMSP, em sua leitura do passado, diz que a proposta inicial era tratar de todos os direitos, porém, priorizando a questão da violência contra a mulher. Isso porque, de acordo com sua narrativa, por trás de todas as discussões está presente a desigualdade de gênero que resulta na apropriação e no controle do corpo feminino. Todos esses discursos que condicionam a mulher a uma posição de assujeitamento podem ser pensados como formas de violência, portanto, enfatiza a importância de se fazer com que essa questão cruze todas as noções de direito. Conforme Amelinha:

\begin{abstract}
A ideia era trabalhar com todos os direitos, desde o começo. Mas focar contra a violência, porque a violência era o problema que impedia a mulher de trabalhar, o que impedia a mulher de ir e vir e impedia a mulher de ter orgasmo, que obrigava a mulher ser mãe ou não ser mãe, porque tinha mulher que não podia tomar o remédio, aliás, ainda tem hoje, mas naquele tempo eu me lembro bem do tanto de mulheres que não podia usar o método contraceptivo porque o marido não deixava e elas não usavam. Ou ela tinha que fazer aborto porque o cara não queria mais ter filho, ou ainda ela era impedida de fazer o aborto porque o filho era dele e ele não queria o aborto! Então tudo isso o que é gente? Nós batalhamos por todos os direitos, mas o que nós tentamos fazer foi passar a
\end{abstract}

3 Carta de Princípios do Curso de Promotoras Legais Populares. Disponível em: <http://uniaodemulheres.org.br/blogpromotoras>. Acessado em: 24/07/2013. 
questão da violência por todos os direitos. Quer dizer violação, violência e descriminalização nós trabalhamos muito juntos, entendeu? São questões separadas, mas que estão imbricadas. Então, o projeto nasceu com essa ideia (TELES, 2012).

Criméia, ao falar sobre o curso, salienta que hoje não se faz mais necessário, como há vinte anos, ter um espaço próprio para que as experiências de violência de gênero emerjam nas narrativas femininas. Atualmente, as mulheres falam mais sobre essas situações, sem se culparem ou se envergonharem como antes. Contudo, ainda persiste uma naturalização dessas agressões sutis e diárias. Desse modo, Criméia diz que o curso possibilita que as mulheres olhem para outras formas de violência, que não apenas as físicas, que também estão presentes em suas vidas e deixam suas marcas.

Ao trazer o olhar feminista e de gênero para o campo jurídico, explora-se a construção do discurso masculino a respeito da mulher, que está presente nas diversas legislações e que não fica ali circunscrito, mas transbordam para suas vidas. É claro, como pontua Criméia, que as discriminações sociais não se reduzem às mulheres, outras minorias também partilham das mesmas, bem como, da falta de acesso à justiça. Entretanto, ela sublinha que o curso visa a trazer à tona as questões de gênero que fazem com que as formas de violência e de descriminalização incidiam, de forma específica, no dia a dia das mulheres.

\begin{abstract}
Bom, essa questão da violência é só juntar mulher que ela aparece, não precisa ser nas PLPs. Agora no curso ela aparece muito porque quando é falado dos diversos ramos do Direito, como da família e do trabalho... E a União sempre procura mostrar como está a mulher no direito da família ou do trabalho, coisas que nem sempre os professores do Direito enfocam bem. E aí não tem como a questão da violência não aparecer e, às vezes, essas mulheres estão procurando uma solução para a vida delas. E sempre que você fala de saúde, trabalho, educação sempre aparece a questão da discriminação contra a mulher, e óbvio que ela aparece com mais intensidade porque o pessoal feminista das promotoras puxa! A discriminação não deixa de ser uma violência. É óbvio que a violência e a discriminação no trabalho também são contra o homem, mas contra a mulher tem um componente a mais, pelo fato de que ela é mulher. Claro que o operário sofre a exploração do patrão, mas quando é mulher tem um "quê" a mais, não é?!(ALMEIDA, 2012).
\end{abstract}

Nessa chave, o curso cria condições para que as participantes enxerguem as diversas formas de hierarquia e desigualdade que são construídas pelos discursos jurídicos. Se, durante os anos de 1980, os movimentos feministas brasileiros politizaram a violência 
contra as mulheres, sobretudo, nos espaços domésticos e familiares, onde há maior ocorrência de casos, hoje, presencia-se, diariamente, o Estado a investir na banalização às agressões cometidas por homens e direcionadas às mulheres, seja com a criação dos JECRIMS, que reprivatizaram a violência doméstica contra as mesmas, seja quando restringe ou inibe a aplicação da atual Lei Maria da Penha.

\section{Os Direitos Humanos e a violência de gênero como pontos centrais}

As agressões, as apropriações violentas e os assassinatos são, sem dúvida, os maiores problemas enfrentados pelas mulheres em diversos pontos do mundo. No relatório da Anistia Internacional, de 2004, consta que as formas de violência direcionada às mulheres são universais, pois acontecem contra ricas ou pobres, negras ou brancas, muçulmanas, cristãs ou de qualquer outra religião. De acordo com o documento, "uma em cada três (mulheres) do planeta já foi espancada, forçada a ter relações sexuais ou submetida a algum outro tipo de abuso". A violência contra a mulher foi considerada como uma violação aos Direitos Humanos a partir do reconhecimento, em 1993, dos Direitos Humanos das Mulheres. Em 1995, durante a Convenção Interamericana para Punir e Erradicar a Violência, em Belém do Pará, a categoria foi definida como "toda e qualquer forma de violência baseada no gênero que cause danos físicos, psicológicos e materiais à mulher" (TELES, MELO, 2002, p.15).

Essas discussões aparecerem no texto elaborado pela UMSP, durante o II Encontro de Violência Doméstica, Sexual e Racial, em 1993, que afirma:

\footnotetext{
Os direitos das mulheres foram reconhecidos porque houve um movimento mundial para denunciar a violência contra a mulher. Foi feito um Tribunal para julgar alguns casos de violência, dentre os quais, um era o Brasil. Esse Tribunal teve o mérito de mostrar que a prática da violência contra a mulher é uma violação aos Direitos Humanos das Mulheres. Ou seja, nós passamos a ser reconhecidas como portadoras dos Direitos Humanos por termos tido a coragem de mostrar nosso rosto torturado pela violência de gênero e não por termos apresentado um trabalho científico, ou outro tipo de manifestação cultural, artística ou política. Fomos reconhecidas como seres humanos a partir do momento que demos visibilidade mundial para a violência doméstica e sexual, uma violência cotidiana praticada contra as mulheres. ${ }^{4}$
}

\footnotetext{
${ }^{4}$ Texto do II Encontro Violência doméstica, sexual e racial. Painel I - Resgate e Reparação, 1993. Arquivo da UMSP.
} 
Entre os anos de 1975 a 1985, as feministas trouxeram para o debate nacional e internacional as discriminações e as formas de violência que cruzam o cotidiano feminino. Abriu-se, então, um diálogo entre os movimentos feministas e os órgãos de Direitos Humanos, o que possibilitou, por exemplo, a criação da Convenção sobre a Eliminação de todas as formas de Discriminação Contra a Mulher (CEDAW), em 1979, que constitui o marco da definição dos Direitos Humanos das Mulheres. Outros encontros foram realizados para firmar esses direitos, tais como a Conferência Internacional das Mulheres, na Cidade do México, em 1975, e a IV Conferência Internacional da Mulher, em Beijin, em 1995.

Esses encontros construíram pontos importantes na defesa dos direitos das mulheres e na tentativa de superação das desigualdades existentes entre os gêneros, nos aspectos sociais, culturais e econômicos, que se refletiram na conquista de leis locais. Em 1996, em uma manifestação na Câmara Municipal de São Paulo, a UMSP defendeu os Direitos das Mulheres como uma violação dos Direitos Humanos e teceu uma crítica ao conceito masculino de humanidade, que não "sexualiza os sujeitos". Segundo o documento, a crítica era decorrente:

(...) da nossa condição de militantes de esquerda, que via com desconfiança a política dos Direitos Humanos, que escamoteava a luta de classes, como na condição de militantes feministas que já percebia o conceito androcêntrico dos Direitos Humanos. Ou seja, na política dos Direitos Humanos o homem é o único paradigma de humanidade. ${ }^{5}$

Apesar do recurso aos Direitos Humanos ser, atualmente, uma ferramenta política dos movimentos sociais feministas, o mesmo enfrenta desafios entre as militantes e não é consenso. Nesse sentido, Braidotti (2010) afirma que, de um lado, os Direitos Humanos são uma espécie de "guarda-chuva" que tenta dar conta de responder às omissões do sistema legal clássico, ou seja, às contradições do capitalismo avançado, à explosão e fragmentação do sujeito na modernidade, enfim, à invisibilidade ou "ilegalidade" que representa uma série de indivíduos sociais flutuantes; por outro lado, falar em tais direitos é preocupante,

\footnotetext{
5 “Os Direitos Humanos das Mulheres: documento apresentado na Câmara Municipal de São Paulo, junho de 1996,
} arquivo da UMSP. 
pois se associa à clássica declaração dos "Direitos Humanos", que é um discurso normativo, branco, eurocêntrico e "muito masculino".

Se, nos anos de 1980, o feminismo pluralizou-se e desfez a categoria monolítica e universal Mulher, apontando para a diversidade de experiências que compõem o indivíduo feminino, como, então, lutar pela (re) afirmação dos direitos representativos desse sujeito? Não estaria o movimento, novamente, caindo em armadilhas linguísticas e impondo valores que fazem parte de uma determinada sociedade a um sujeito universal denominado de Mulher? Quais caminhos seguir para que haja um reconhecimento social de que as mulheres partilham de determinadas experiências que devem ser erradicadas, a exemplo da apropriação violenta e sexual dos seus corpos, sem cair em guetos conceituais ou nos discursos do relativismo ou da imposição cultural?

Contudo, não se pode negar que as mulheres, sejam elas brancas, negras, ricas, pobres, religiosas ou não, partilham de uma série de apropriações e regulamentações de seus corpos e de sua sexualidade. Entretanto, a normatização universal dos direitos chocase com costumes locais e há a necessidade de uma negociação. Assim, há de se problematizar de que modo e até que ponto os Direitos Humanos das Mulheres interferem nas situações políticas, mas, sobretudo, na autonomia destas em relação a uma prática legitimada tanto pelo Direito quanto pelos processos culturais.

Flávia Piovesan (2012), advogada, feminista e defensora dos Direitos Humanos das Mulheres, avalia que os mesmos não constituem uma forma de imposição ou de relativismo cultural, mas uma maneira de colocar as questões de gênero no discurso jurídico e de propor a alteração dos paradigmas e valores deste campo. Desse modo, a autora afirma que:

\footnotetext{
Neste cenário as mulheres devem ser vistas nas especificidades e peculiaridades de sua condição social. Ao lado do direito à igualdade, surge, como direito fundamental, o direito à diferença. Importa o respeito à diferença e à diversidade, o que lhes assegura um tratamento especial. O direito à diferença implica o direito ao reconhecimento de identidades próprias, o que propicia a incorporação da perspectiva de gênero, isto é, repensar, revisitar e reconceptualizar os Direitos Humanos a partir da relação entre os gêneros, como um tema transversal (PIOSEVAN, 2012).
}

A UMSP trabalha com a perspectiva dos Direitos Humanos para as mulheres e partilha das concepções apontadas por Piovesan. Amelinha, em seu livro $O$ que são os 
Direitos Humanos das Mulheres (2007), que é representativo da posição da associação, enfatiza que tratar de políticas públicas por esse caminho é estender visibilidade a setores sociais excluídos ou vulneráveis, como mulheres, crianças, populações negras e indígenas, imigrantes, gays, lésbicas, transexuais, entre outros. É um modo de reconhecer, juridicamente, a existência desses indivíduos, tratados, em muitas sociedades, de forma marginal e abjeta. Para Amelinha, o principal ponto desse recurso é sua universalidade, que permite estabelecer que esses indivíduos marginalizados sejam reconhecidos, também, como humanos.

De acordo com as pesquisas realizadas por Bonetti (2010), essa é uma linha de atuação de outros movimentos feministas brasileiros, a exemplo da ONG Cidadania, Estudo, Pesquisa, Informação e Ação (CEPIA) e do Centro Feminista de Estudos e Assessoria (CFEMEA). Portanto, o termo embute uma categoria política que tem sido utilizada pelos feminismos como forma de criticar o caráter sexista do discurso jurídico centrado na figura masculina do cidadão. Assim, afirma que a ênfase dada a esse discurso leva em conta "os obstáculos legais do sistema jurídico brasileiro", quando se trata "de questões como aborto, violência doméstica e violência sexual" (BONETTI, 2010, p. 46)

Como, atualmente, a violência contra as mulheres é um dos principais problemas a serem enfrentados pelos movimentos feministas, o curso de PLPs estimula, por um lado, por meio da defesa dos Direitos Humanos das Mulheres, o reconhecimento das assimetrias culturais que convergem em cenas múltiplas de violência; por outro, a participação das mulheres em ações que pressionam o Estado contra o tratamento dispensado às situações de violência e de discriminação contra as mulheres. Oliveira (2006) destaca que o Direito, como "espinha dorsal" do curso, funciona como um meio de "empoderar" as mulheres para que elas passem a reconhecer seus direitos, mas, sobretudo, para que percebam seu lugar na sociedade e comecem a "nomear violações e violências antes inomináveis" (2006, p.71). A partir do conhecimento sobre as formas de violência e as normas jurídicas a respeito das mesmas, as participantes podem reconhecer como suas experiências de violência são tratadas pelo Estado e, assim, criar estratégias de luta por formas outras de tratamento em situações de conflito.

É nesse contexto que Terezinha, militante e fundadora da UMSP, inscreve sua percepção sobre a relevância do projeto na desnaturalização da violência. Em sua narrativa, 
ela diz que, dentro da chave "violência de gênero", o grupo trabalha as definições de violência doméstica, sexual, assédio moral, a atual Lei Maria da Penha e a história da luta feminista, para fazer emergir cenas de agressões, ao lado da conquista dos direitos das mulheres. Essas aulas, como explica, são acompanhadas por oficinas de troca de experiências, estudos de casos e visitas a órgãos públicos, como a Delegacia de Defesa da Mulher ou o núcleo da Defensoria Pública da Mulher. Isso, em sua leitura, tem um "peso forte" para que as mulheres conheçam as formas de discriminação que cortam suas vidas e, assim, não tratem essas situações como normais. Segundo ela:

\begin{abstract}
A mulher só vai deixar de apanhar e de morrer assassinada no dia em que tiver democracia de direitos. E aí o projeto de promotoras populares estuda a constituição, os direitos humanos, que são indivisíveis. Isso é uma questão que a gente coloca forte como a do direito machista. A discussão para transformar a legislação de direitos em políticas públicas, o acesso mesmo aos direitos. Então, é fundamental o projeto no sentido de fortalecer as mulheres, de empoderar as mulheres (GONZAGA, 2012).
\end{abstract}

Conhecer os direitos é entendido como um instrumento que permite às mulheres transformarem suas vidas, no sentido de se reconhecerem dentro de um processo cultural e social que as relega a determinadas situações de marginalização e exclusão, ou, ainda, como agentes transformadores das relações sociais que as cercam. Para ilustrar como o processo de educação jurídica possibilita às integrantes criar pontes para acessar seus direitos, abordarei, a partir das memórias de Terezinha, o caso de uma jovem que foi estuprada em seu local de trabalho e que levou sua experiência para ser discutida no curso de PLPs.

Terezinha, em entrevista, conta que uma jovem, Luciana, procurou a UMSP para denunciar o estupro perpetrado por seu então patrão, proprietário de uma rede de lojas de calçados localizada no centro de São Paulo. Ao realizar a denúncia na Delegacia de Defesa da Mulher, Luciana descobriu que outras colegas de trabalho haviam passado pela mesma experiência e desistiram do processo por terem sido acusadas de provocarem a violência. Diante disso, ela resolveu procurar a UMSP para saber quais caminhos ela poderia seguir para que seu agressor não ficasse impune. Além disso, como discutido por diversos pesquisadores da área da saúde, a violência física ou sexual desencadeia muitos 
problemas de saúde nas vítimas e, nesse caso, a jovem desenvolveu transtornos psicológicos que a levaram a um quadro de depressão.

Ao rememorar este caso, Terezinha narra que essa experiência foi de grande importância para o reconhecimento da violência sexual no trabalho e para a efetivação dos direitos das mulheres. $\mathrm{O}$ caso da jovem foi discutido com os professores que ministravam a aula no curso de PLPs e com as demais alunas. Das reflexões, surgiu a ideia de entrar com dois processos contra o agressor, um penal e outro trabalhista. No caso deste último, Luciana conseguiu entrar com um pedido de CAT (Comunicado de Acidente de Trabalho), que, até então, não incorporava a violência de gênero como possibilidade. ${ }^{6}$ Terezinha recorda:

\begin{abstract}
Foi um caso em que ela se propôs a ir no curso de Promotoras justamente no dia em que a pessoa que deu aula trabalhava na secretária da saúde do trabalhador e sugeriu, junto com o jurista que estava na mesa com ela, fazer uma CAT e aí fez e foi aceito. E eu acho que nunca ninguém tinha colocado dessa forma. $E$ foi um marco! Ela ficou com síndrome do pânico, tinha sempre que mudar de casa, ela ficou bem traumatizada, então a CAT foi fundamental. Os problemas psicológicos foram consequência do estupro. E teve uma repercussão tão grande que a revista da FIESP fez uma matéria alertando os empresários a tratarem da questão, para evitarem. Então, foi uma coisa muito interessante essa referência. Nós levamos o caso para o encontro de saúde e da mulher trabalhadora. (GONZAGA, 2012).
\end{abstract}

Esse caso é representativo das diversas faces que a violência de gênero assume no cotidiano feminino e ilustra como o projeto de PLPs fornece bases para que as mulheres consigam reconhecer as desigualdades presentes em suas vidas e criar estratégias de luta pelos seus direitos. É claro que o curso também tece uma crítica ao Direito, afinal, não se pode concebê-lo como um campo "mágico", capaz de dar conta das soluções dos problemas das mulheres. $O$ discurso do grupo caminha ao lado das posições feministas que veem o espaço jurídico como um lócus de luta pelo reconhecimento de outras experiências. Portanto, busca-se alterar o discurso normativo do Direito a fim de que determinadas práticas já existentes na sociedade sejam reconhecidas e não perseguidas criminalmente, como no caso do aborto, ou tratadas de forma banal, como a violência de gênero.

\footnotetext{
${ }^{66}$ Ver: MELO, Mônica “Estupro e Acidente de Trabalho”. In: Instituto Brasileiro de Advocacia Pública. Disponível em: <http://cienciaspenaisemdebate.blogspot.com.br/2011/09/estupro-e-acidente-de-trabalho.html>. Acesso em: $26 / 07 / 2013$.
} 
A advogada feminista e também uma das fundadoras da Themis, Carmen Campos, partilha dessa concepção. Ao narrar sobre a perspectiva de luta no campo jurídico, enfatiza que o Direito, em si, não é um mecanismo de luta para as feministas, pois reconhece que a alteração das leis não trará mudanças efetivas para as relações de gênero. Contudo, em sua percepção, o Direito é um espaço de luta para os feminismos e outros movimentos sociais, pois o combate travado, nesse âmbito visa ao reconhecimento da multiplicidade de experiências dos indivíduos. Nesse sentido, ela afirma que:

\begin{abstract}
Por tempos discutimos se o Direito pode ser um instrumento de mudança. E eu dizia o seguinte: o Direito não é um instrumento de mudança, ele é um lugar de luta. Não adianta a gente fazer a lei, nós não vamos mudar com a lei, o que nós vamos fazer é mudar uma concepção jurídica sobre determinado assunto. Porque o fato existe, o fato na vida já mudou. Por exemplo, o Direito proíbe o aborto, mas as mulheres fazem o aborto. A vida é muito mais rápida, muito mais complexa, apresenta muitas outras situações que o Direito não dá conta. Então não é o Direito o instrumento da mudança. A mudança é claro, tem um impacto na vida. Se descriminalizar o aborto terá um impacto. Mas é o impacto do ponto de vista jurídico, as mulheres não vão ser mais perseguidas criminalmente, as relações homoafetivas poderão ter reconhecimento jurídico em outros campos, então se adéqua a realidade (CAMPOS, 2011.)
\end{abstract}

O curso de PLP, desse modo, possibilita que as participantes percebam como o discurso jurídico, ao lado de outros, constrói a "identidade" feminina sob uma sujeição a valores patriarcais e misóginos. Do mesmo modo, as alunas podem interrogar por que elas, assim como indivíduos de outros segmentos sociais, não se veem como portadores de direitos, mesmo que existam leis que afirmem o contrário. Assim, ao descontruir a linguagem formal do Direito, o curso democratiza os direitos dos indivíduos e desfaz a percepção de que o espaço jurídico é um lócus sagrado e inacessível à população. Essa posição fica evidente no depoimento de uma participante do curso, em 1996. No documento, Maria de Fátima, moradora da Favela da Boa Esperança, avalia:

O curso me esclareceu e me fez ver pessoas que antes eu achava que eram bichos de sete cabeças, como juízes, promotores, procuradores e advogados. 0 importante no curso é aprender a ir ao lugar certo, seja na polícia ou no judiciário, falar com a pessoa certa. Conhecer o que devem fazer juiz, promotores, delegados. (...) Nós, Promotoras Legais Populares precisamos saber de tudo isso para ajudar as pessoas a acompanhar um processo e conseguir uma solução (...) eu estou trabalhando os direitos das mulheres, porque são elas que me procuram. Para fazer uma separação, um divórcio ou tratar de pensão 
alimentícia, ou mesmo para atender um jovem preso, são sempre as mulheres que tomam a iniciativa de ir buscar ajuda ou orientação. ${ }^{7}$

Essa relação entre as experiências femininas, o conhecimento das leis e a "posse" sobre elas faz com que muitas participantes não apenas rompam o status que o Direito ocupa na sociedade, mas também tenham outra perspectiva em relação à família, ao trabalho e à maneira como se veem no mundo. A desconstrução da linguagem jurídica opera como agente transformador, para que as mulheres se reconheçam dentro de um processo histórico e cultural de sujeição e de definição da função de seu corpo, de sua sexualidade e de seu prazer por discursos masculinos. Para muitas mulheres, opera como o desvendar de novos horizontes, de modo que passam a almejar outros caminhos de vida.

\section{As mudanças subjetivas}

O conhecimento jurídico permite, também, que essas mulheres desenvolvam outros olhares para suas relações familiares, afetivas e para seus cotidianos. Muitas, ao ingressarem no curso, passam a cuidar de si próprias de forma muito mais evidente. Como afirma Oliveira:

(...) muitas mulheres, além da aquisição do conhecimento em si, propriamente jurídico, vão mudando outros aspectos da sua vida, como terminar um relacionamento que não ia bem ou voltar aos estudos. Além disso, percebi que muitas delas, ao longo do curso, se tornam mais vaidosas, iam bem arrumadas e com os cabelos penteados. (...) Essa ideia de empoderamento é ampla, pois, contempla, deste modo, pequenas transformações da vida até a ocupação de espaços públicos (2006, p.21)

Do mesmo modo, Ricoldi (2005) assinala que o "aumento da autoestima" é enfatizado pelas mulheres que chegam ao final do curso, pois o processo de fazer parte de um grupo e conhecer a historicidade das desigualdades tidas como naturais, até então, em suas vidas, faz com que haja, em muitos casos, processos de ruptura com antigos valores. Pinto, ao refletir a respeito do pertencimento de indivíduos em movimentos sociais, avalia que o sentimento de adesão leva a processos de transformação do indivíduo em outro, o que desencadeia diversos choques e rupturas.

\footnotetext{
${ }^{7}$ Depoimento de Maria de Fátima Miranda. Caderno da "Coordenação de Promotoras Legais Populares". União de Mulheres de São Paulo, 1997, p. 19. Arquivo UMSP.
} 
As relações de amizade e solidariedade também foram pontos perceptíveis nas afinidades que se estabeleceram. Pertencer ao grupo denominado de "Promotoras Legais Populares" e compartilhar experiências de vida que são comuns possibilita a criação de "laços de solidariedade, não para se vitimizar, mas para (...) promoverem transformações individuais e coletivas" (OLIVEIRA, 2006, p.23). Há um processo de identificação das formas de exclusão e assimetrias que convergem em seus cotidianos, o que permite a construção de uma rede de amizade e companheirismo e desperta desejos por transformações de si e do outro.

Por essa via, muitas das entrevistas afirmaram mudanças significativas em suas vidas, bem como, o desejo pela militância. Como o curso não é um espaço apenas de transferência de informações, mas um lócus de expressão da política feminista, muitas das participantes, ao se identificarem com o discurso da entidade, demonstraram o desejo de dar continuidade ao ativismo. Assim, elas passaram a trabalhar em suas comunidades e bairros, atendendo mulheres vítimas de violência, ensinando direitos básicos à população e lutando pela melhoria das condições de vida.

Os feminismos têm se rebelado contra as visões tradicionais ligadas à identidade feminina domesticada e têm valorizado outras práticas corporais, afetivas, assim como, outras formas de se pensar a família. É nessa perspectiva que Norma, uma "chilena baiana", como se denomina, percebe as mudanças efetuadas em si pelas relações estabelecidas no curso de PLPs. Norma Cubillos é chilena, mãe de oito filhos, e mudou-se para o Brasil em 1981. Ela narra que a participação no curso de PLPs a "libertou" da identidade tradicional da mulher que deveria viver para o cuidado com os filhos e com o marido, ou seja, do dispositivo amoroso teorizado por Swain (2011). Em sua narrativa, ela afirma que:

\footnotetext{
Antes de conhecer as Promotoras Legais eu era uma mulher presa ao matrimônio. Porque eu tinha que ser uma mulher companheira, servir e tudo. $E$ depois quando eu comecei a entrar para os movimentos, que conheci as Promotoras Legais foi que eu me libertei que eu conheci meus direitos, que a mesma responsabilidade que eu tenho com os filhos, ele também tem (CUBILLOS, 2010).
}

Norma reside em Mauá, onde participou, pela primeira vez, do projeto de PLPs, em 2009. Em sua leitura, foi por meio dessa experiência que se tornou "mais independente e autônoma". Após o curso, voltou a estudar, entrou para a militância feminista e rompeu 
com seu segundo marido. Em sua fala, o desejo de promover mudanças também aparece de forma expressiva, portanto, enfatiza que tem se dedicado "falar com outras mulheres", para que essas possam partilhar dos mesmos aprendizados.

Esse desejo de militar e lutar pelos direitos das mulheres e de outros setores marginalizados também aparece na narrativa de Wilma Souza, atualmente, ativa militante da UMSP. A artesã e artista plástica fez o curso de PLPs em 2009, o que, segundo seu depoimento, mudou, radicalmente, sua vida. Ao contrário de muitas entrevistadas, ela não rompeu com o casamento, mas transformou a maneira pela qual se via como mãe e como esposa e, também, a percepção que seus filhos e seu marido tinham de sua função em casa. Segundo ela:

\begin{abstract}
Na minha família mexeu assim, eu tenho três homens na minha casa, então, a cabeça deles também mudou, eles pensam diferente em relação à mulher, em dizer que minha mulher é do lar, minha mãe é a rainha do lar! E eu também consegui mudar isso em mim, eu sempre digo assim que eu fui acendendo as gavetinhas, aquelas gavetas está num canto e a gente nem vê! Eu comecei a prestar mais atenção em mim, no meu corpo, porque a gente não tem costume, e eu aprendi que a gente tem que se olhar. (SOUZA, 2012).
\end{abstract}

Além das mudanças dos olhares sobre si, Wilma diz que muitos dos preconceitos que tinha em relação à prática do aborto e à homossexualidade foram rompidos. Ela avalia que a aula que mais a tocou foi a ministrada por Valéria Busin, ativista das Católicas pelo Direito de Decidir e do movimento LGBT. Em sua leitura, essa aula desfez as visões que possuía sobre o feminismo e as relações homoafetivas: "porque, na minha cabeça, feminista era aquela mulher que ia para a rua queimar sutiã, era lésbica, eu tinha um preconceito muito grande" (SOUZA, 2012).

Assim como Norma, Wilma e sua filha Anna Carolina manifestaram o desejo pela militância. Isso porque, em suas narrativas, a política feminista é vista como algo que não se encontra apenas em espaços institucionais, mas, principalmente, nas atitudes cotidianas, pois, por meio da fala, as mulheres podem ensinar, orientar e trocar experiências, construindo uma teia que possibilita mudanças em si própria e no outro. A experiência de Norma, marcada pelas relações assimétricas de gênero, classe, etnia e pela sua condição de "imigrante", faz com que ela deseje levar a outras pessoas a possibilidade de se constituírem de forma distinta. Já Wilma e Anna Carolina promovem debates e 
oficinas sobre violência doméstica e aborto em seu bairro, além de prestarem "atendimento" a mulheres em situação de violência.

Anna Carolina, que, na época da entrevista, tinha dezoito anos e cursava o primeiro ano da faculdade de administração, narra que, na militância que exerce ao lado de sua mãe, o maior nó a se desfazer, na mentalidade cultural, ainda é o da violência de gênero. Ela argumenta:

Porque tem mulher na minha comunidade que apanha e aí nós vamos lá socorrer. Às vezes, tem mulher que bate na porta da minha casa às onze horas da noite, chorando, com o olho roxo, falando aconteceu isso e aquilo. E aí a gente vai para a delegacia, vai para defensoria, para onde for preciso. Aí a gente socorre e ela apanha de novo e aí veem dizer: "é, mas ela apanha porque ela quer!" E eu tento ir lá dizer não é assim que se resolvem as coisas, ela está presa há alguma coisa ali. Por exemplo, essa semana no curso da faculdade chegou uma menina falando que acordou às 7 hs da manhã porque a vizinha estava apanhando e ela não sabia o que fazer. Aí eu peguei a caderneta anotei meu telefone, o que ela tiver que procurar e mesmo para desabafar. (SOUZA, 2012).

O aprendizado do curso, assim, não abre apenas um espaço para as mulheres olharem para suas vidas de forma diferente, dando novos significados para suas experiências, mas também para reatualizarem sua concepção de política, que não se restringe aos espaços institucionais, abrindo-se para pequenas revoluções que são feitas diariamente no cotidiano feminino. A UMSP, hoje, não consegue comportar todas as mulheres que saem do curso e que querem dar continuidade à militância, porém, como pondera Terezinha, essas, muitas vezes, passam a atuar em suas comunidades ou mesmo, a se unir e constituir novos espaços de ativismo, a exemplo dos cursos de PLPs que se espalharam pelo estado de São Paulo.

\section{Considerações Finais}

Nas últimas décadas, vimos os feminismos provocarem intensas modificações na vida social e cultural das mulheres, pois estas ocupam, hoje, novos postos de trabalho e possuem maior grau de escolaridade. Isso se reflete nas participantes que encontrei no curso de PLPS, promovido pela UMSP. Elas têm idade e escolaridades diferentes, do mesmo modo, apesar de grande parte pertencer às camadas mais pobres da cidade, não é raro encontrar alunas da classe média e com formação universitária. Entretanto, o que 
chama a atenção é o fato de que essas mulheres, ao contrário do que ocorria algumas décadas atrás, trabalham, estudam e saem de suas casas em um sábado de manhã para fazer um curso, que, para muitas, pode trazer novos aprendizados ou mesmo lhes oferecer novas concepções para sua área profissional. Há, entre elas, muitas senhoras, donas de casa, que veem no curso uma chance de aprender o que, por muito tempo, lhes foi negado, e isso faz com que muitas voltem para os bancos escolares.

Contudo, mesmo diante de inúmeras transformações no cotidiano dessas mulheres, não se pode esquecer que há, ainda, inúmeros discursos que seguem investindo na domesticação da subjetividade feminina. Portanto, quando se trata de mudanças de ordem política e social, deve-se levar em conta que ainda há resistências em se alterar o imaginário cultural a respeito das mulheres, haja vista, sobretudo, a questão da violência de gênero. Nessa direção, o curso de PLP atua como um agente de transformação, tanto da percepção que as mulheres têm sobre a violência que recorta seu cotidiano, bem como, da própria subjetividade feminina, pois, como afirmam Bonetti et.al. (2002), "a apropriação do universo dos direitos [...] possibilita a transformação pessoal de cada mulher". Nesse contexto, muitas das participantes passam a olhar de forma diferente para si e para suas vidas, dispensam um cuidado maior para si mesmas e começam a questionar alguns aspectos de seu cotidiano. As relações de amizade e companheirismo também são visivelmente fortalecidas, assim como, o desejo pela militância.

Em suma, ao contrário do que se ouve, os feminismos ainda são de suma importância para enfrentar os discursos patriarcais e misóginos que não cessam de tentar colonizar a subjetividade feminina. Tratando-se do curso de PLPs, o aprendizado sobre os processos normativos que instituem a "identidade mulher" e que constroem as subjetividades femininas e masculinas, com uma base binária e hierarquizada, resultando em formas de autorização para a violência, possibilita que as mulheres passem a enxergar com outros olhos as discriminações que ocorrem em suas vidas e a construir estratégias para que os direitos humanos e das mulheres não fiquem apenas "no papel", mas se reflitam em soluções para os problemas enfrentados por elas e por suas comunidades no dia a dia. Do mesmo modo, a participação no curso permite que grande parte das mulheres realize pequenas transformações em si mesmas, isto é, que construam outros olhares para suas vidas e suas relações. Desse modo, o aprendizado construído pelas PLPs possibilita que 
muitas das mulheres, ali presentes, construam uma nova maneira de se ver no mundo, almejando a transformação não apenas de si, mas também do seu entorno.

\section{Bibliografia}

BONETTI, Alinne. Entre feministas e mulheristas: uma etnografia sobre as Promotoras Legais Populares e as novas configurações da política feminista em Porto Alegre.

Dissertação de mestrado, Universidade Federal de Santa Catarina, Florianópolis, 2010.

BONETTI, Alinne et.al. Percurso da Cidadania: da capacitação legal à promoção e garantia dos direitos humanos das mulheres". IN: DORA, Denise (org.). Direito e Mudança Social projetos de promoção e defesa dos direitos apoiados pela Fundação Ford. Direito e Mudança Social - projetos de promoção e defesa dos direitos apoiados pela Fundação Ford. Rio de Janeiro: Renovar, 2002.

BRAIDOTTI, Rosi. Feminismo, Diferencia sexual y subjetividad nómade. Barcelona: Gedisa Editorial: 2010.

CAMPOS, Carmem. Teoria Feminista do Direito e Violência Intima contra as Mulheres. EMERJ, Rio de Janeiro, v.15, n57, jan./mar. de 2012.

GREGORI, Maria Filomena \& DEBERT, Guita. Violência e Gênero: novas propostas, velhos dilemas. Revista Brasileira de Ciências Sociais. Vol. 23 no 66, 2008.

MC CLYMONT, Mary \& GOLUB, Stephen (Org.) Many Rods to Justice: The Law Related Work of Ford Foundation Grantees around the World. United States of America: The Ford Foundation: 2010.

OLIVEIRA, Fernanda Fernandes. Quando o Direito Encontra a Rua. Dissertação de Mestrado, Faculdade de Educação, Universidade de São Paulo, 2006.

RAGO, Margareth. Feminizar é preciso: por uma cultura filógina. IN: São Paulo em perspectiva, v. 15, n. 3, p. 58-66, 2001.

RICOLDI, Arlene. A experiência da Promotoras Legais Populares em São Paulo. Dissertação de Mestrado, Departamento de Sociologia, Universidade de São Paulo, 2005.

ROSERO, R. Feminismo y educación popular. IN: Crecer juntas: mujeres, feminismo y educación popular - América Latina y Caribe. Isis Internacional, Red de Educación Popular entre Mujeres, Santiago, 1987.

SCHULER, Margaret, KADIRGAMAR-RAJASINGHAM, Sakuntala. (Orgs.) Legal Literacy: a Tool for Women's Empowerment. New York: UNIFEM, 1992. 
SWAIN, Tania Navarro. Diferença sexual: uma questão de poder. IN: Conferencia do I Simpósio de Gênero e Literatura, Universidade Federal do Ceará, agosto de 2011. Disponível em: <http://www.tanianavarroswain.com.br>. Acessado em: 26/07/2013.

TAMAYO, Giulia. Trazos y recorridos/sobre gênero, derecho y desarrollo. IN: Capacitación legal a mujeres. CLADEM, Lima: Peru, 1991.

TELES, Maria A.; MELO, Monica. O que é violência contra a mulher? São Paulo: Editora Brasiliense, 2002.

TELES, Maria Amélia A. O que são os Direitos Humanos das Mulheres. São Paulo: Editora Brasiliense, 2007.

\section{Entrevistas}

DANDARA, Coletivo. Entrevista com Maria Amélia A. Teles. São Paulo, agosto de 2009. Disponível em: <http://www.centrodandara.org.br>. Acessado em: 26/07/2013.

Entrevista com Anna Carolina Souza Dias. São Paulo, 17 de março de 2012 (38 min.). Entrevista com Carmen Hein Campos. Porto Alegre, 31 março de 2011 (98 min.). Entrevista com Criméia Alice Schmidt de Almeida, São Paulo, 19 de abril de 2011 (94 min.).

Entrevista com Criméia Alice Schmidt de Almeida, São Paulo, 05 de fevereiro de 2012 (53 min.).

Entrevista com Maria Amélia de Almeida Teles, 22 de fevereiro de 2011 (137min.).

Entrevista com Maria Amélia de Almeida Teles, São Paulo, 12 de janeiro de 2012 (81 min.).

Entrevista com Norma Cubillos, São Paulo, 20 outubro de 2011 (28 min.).

Entrevista com Terezinha de Oliveira Gonzaga, São Paulo, 02 maio de 2010 (131 min.).

Entrevista com Terezinha de Oliveira Gonzaga, São Paulo, 12 de janeiro de 2012 (59 min.).

Entrevista com Wilma Souza, São Paulo, 17 de março de 2012 (36 min.). 